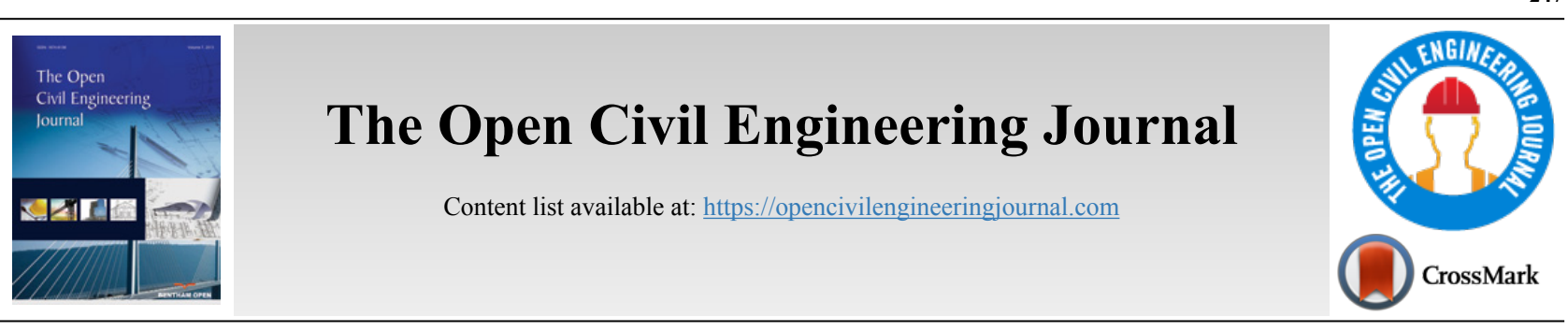

RESEARCH ARTICLE

\title{
Effect of Gravel-sand Ratio on Physico-mechanical, Thermal and Macro- structural Properties of Micro Epoxy Polymer Concrete based on a Mixture of Alluvial-dune Sand
}

\author{
Zineb Kerrida $^{1}$, Hichem Berkak ${ }^{1}$, Zoubir Makhloufi ${ }^{1}$, Madani Bederina ${ }^{1, *}$ and Ahmida Ferhat ${ }^{1}$

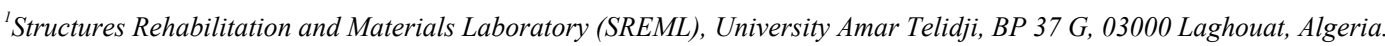

\begin{abstract}
:
Introduction:

In the Polymer Concrete (PC) composites, aggregates are the most important constituent, which considerably affect their performance. The purpose of this experimental study is to examine the effect of Gravel-to-Sand $(\mathrm{G} / \mathrm{S})$ ratio on the physico-mechanical, thermal and microstructural properties of epoxy micro-polymer concrete made up of local aggregates.

Materials \& Methods:

The Micro Epoxy Polymer Concrete (MEPC) studied consists of epoxy resin as a binder and a mixture of two types of sands (alluvial ( $0 / 0.63$ mm) and dune $(0 / 4 \mathrm{~mm})$ sands), as well as crushed limestone gravel $(3 / 8 \mathrm{~mm})$. Six compositions were prepared with two epoxy resin contents $(10 \%$ and $14 \%$ of the total weight of mixture) and three $\mathrm{G} / \mathrm{S}$ ratios $(0.25,0.50$ and 0.75$)$. The studied properties are density, water absorption, compressive and flexural strengths, thermal conductivity, thermal diffusivity, specific heat and macrostructure.

Results \& Discussion:

The obtained results show that the G/S ratio, as well as the epoxy resin content, has a significant influence on the properties of MEPC. In addition, $14 \%$ epoxy resin and the G/S ratio of 0.75 can be considered as optimal values, which lead to very interesting physico-mechanical performances (denser and less porous material, more resistant with almost similar thermal conductivity). Moreover, the density, the water absorption and the optical microscopic observation confirm that mixes containing $14 \%$ epoxy are more impermeable, compact and homogeneous than those containing $10 \%$ epoxy.

Conclusion:

Finally, it should be noted that the incorporation of aggregates being relatively coarse decreases the grains' specific surface and reduces the porosity of the granular mix, which enable the epoxy product to completely cover the surface of mineral grains. A perfect covering of aggregate grains with a bender improves the adhesion between the aggregates and the polymer matrix.
\end{abstract}

Keywords: Micro-polymer concrete, Epoxy resin, Gravel-to-sand ratio Thermal properties, Alluvial-dune sand, Mechanical and physical properties, Macrostructure.

Article History

Received: June 19, 2020

Revised: August 10, 2020

Accepted: August 18, 2020

\section{INTRODUCTION}

The use of Polymer Concrete (PC) is one of the strategies followed to limit the use of ordinary cement concrete in applications requiring high tensile strength or excellent resistance to certain extreme conditions [1]. The Polymer Concrete (PC) is a composite consisting of a polymer resin binder and a mixture of aggregates [2]. Despite its relatively

\footnotetext{
* Address correspondence to this author at Structures Rehabilitation and Materials Laboratory (SREML), University Amar Telidji, BP 37 G, 03000 Laghouat, Algeria; Tel: 00213773732230; E-mail: m.bederina@lagh-univ.dz
}

high cost, epoxy is one among the most preferred and used resin binders in the production of $\mathrm{PC}$, due to its excellent properties [3, 4]. The achievement of better mechanical characteristics, stronger adhesion, lower shrinkage as well as easer in situ application, has extended the use of Epoxy Polymer Concrete (EPC) in the construction sector [5, 6].

Until now, a great effort in terms of experimental research has been devoted to the characterization of the physical, mechanical, thermal and durability properties of EPC [5, 7 - 9]. Moreover, the performances of EPC heavily depend on the 
amount of polymer binder, the type of aggregates and their size distribution, the reinforcement (fillers and fibers), the quality of the adhesion between components, etc [8, 10 - 12]. Aggregates and fillers typically occupy more than $40-80 \%$ of the volume of PC $[10,13]$, and they also play a key role in the mechanical and other properties [14]. These aggregates are generally of natural or industrial origin, or waste materials [15]. According to the literature, several researchers have favored the use of locally available aggregates, such as river sand and crushed stone, in order to reduce the cost of PC products $[1,3,14,16]$.

Various research works $[12,17]$ have been carried out to study the influence of natural aggregates on the behavior of PC in the fresh state and hardened state and in chemically aggressive environments. An optimized aggregate mix proportion with a minimum void content results in a considerable decrease in the binder content, without compromising the properties of $\mathrm{PC}$, making the system more costeffective $[12,17]$. Shigang et al. [18], found that the aggregate geometrical shape has a significant impact on the failure behaviors of PC. When the aggregates have a small number of edges, they will have more sharp angles inducing a higher stress concentration during the loading and the micro-cracks will, therefore, be more easily generated in these locations, which reduce the resistance of PC. The optimal percentage of a resin polymer in the PC system depends on the nature of aggregates used. Let us note that, when using fine aggregates, it is recommended to increase the resin dosage, because of their large surface area [19, 20]. Ferdous et al. [1], noted that the distribution of aggregates in the EPC strongly depends on the resin / charge ratio of the mixture. When the resin content is more than $60 \%$, the aggregates are uniformly distributed throughout the entire depth of the PC, due to the increased fluidity of the epoxy matrix. On the basis of the experimental and simulation results of the packing density, an optimization study of gravel percentage in PC was carried out. The optimal packing density was obtained with gravel contents of $35-55 \%$. However, the value of $35 \%$ of gravel and $65 \%$ of sand $(\mathrm{G} / \mathrm{S}=0.54)$ was retained in order to improve the workability of EPC [3]. On the other hand, Haidar et al. [8], developed a Micro-Polymer Concrete (MPC) based on a mixture of coarse and fine aggregates of granular sizes of 2-4 mm and 0-1.25 mm respectively. They reported that the MPC which was designed with a $\mathrm{G} / \mathrm{S}$ ratio of 0.25 and an epoxy content of $9 \%$ has higher physicomechanical characteristics. Furthermore, Shokrieh et al. [21], reported that the effect of the epoxy resin content on the compressive / flexural strengths and the interfacial shear strength between PC and steel, is more significant than the effects of aggregate size and percentage of chopped glass fibers.

Moreover, Nogueira et al. [22], studied the effect of water absorption on the mechanical properties of an epoxy resin system and found that the increase in absorbed water led to a gradual decrease in the tensile properties.

In another context, it should be noted that the fine and coarse alluvial aggregates are becoming depleted and therefore, their cost is considerably increased. In addition, the extraction of these aggregates poses a real ecological problem, so that government regulations in many countries prohibit the overuse of these aggregates [23]. In contrast, crushed limestone sands, as well as dune sands, are widely available in the Laghouat region and remain largely unexploited $[24,25]$. In fact, the use of these local materials provides an opportunity to mitigate the high cost of the EPC and decreases the environmental impact of these composites.

The main objective of this study is to optimize the composition of a Micro Epoxy Polymer Concrete (MEPC) using local aggregates (alluvial - dune sand and crushed limestone gravel). The purpose is to seek the optimal values of the epoxy resin content and the G/S ratio. The optimization of these factors may have interesting implications in terms of performance and cost. Let us note that, in previous research, different aggregates were used in the preparation of $\mathrm{PC}$, but the use of dune sand in this concrete type has not been studied previously. The use of this new material in MEPC is part of the valorization of local materials and highlights; indeed, the originality of this study [26, 27].

The optimization of MEPC was carried out on the evaluation of its mechanical (compressive and flexural) strengths and thermal properties, density, water absorption capacity and the macrostructure. In addition, the combination of these tested parameters will allow us to develop more costeffective and durable MEPC as small-scale building materials such as roof and floor tiles and for repairing damaged concrete surfaces at shallow depth.

\section{MATERIALS AND EXPERIMENTAL INVESTIGA- TION}

\subsection{Materials and Sample Preparation}

The studied Micro Epoxy Polymer Concrete (MEPC) was prepared using a mixture of local natural aggregates with a maximum size of $6 \mathrm{~mm}$ and epoxy resin. These different components are characterized below.

\subsubsection{Aggregates}

A mixture of two different types of local natural sand was used as fine aggregate. The first is alluvial sand (AS) (Fig.1a) obtained from the M'zi river running through the city of Laghouat (South of Algeria). The second is dune sand (DS) (Fig.1b) also from the same region. The granular classes of AS and DS are $(0 / 0.63 \mathrm{~mm})$ and $(0 / 4 \mathrm{~mm})$, respectively. 


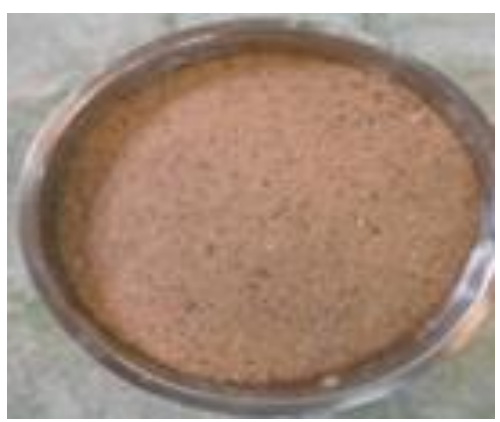

a (AS)

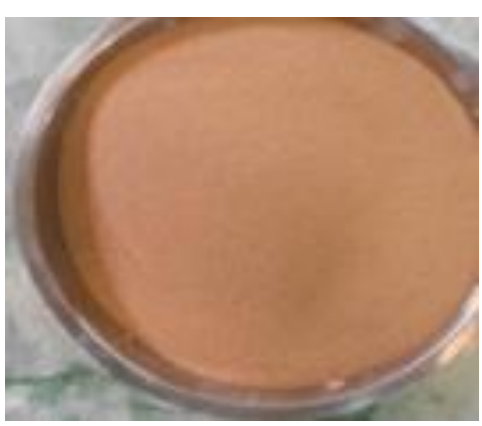

$\mathrm{b}$ (DS)

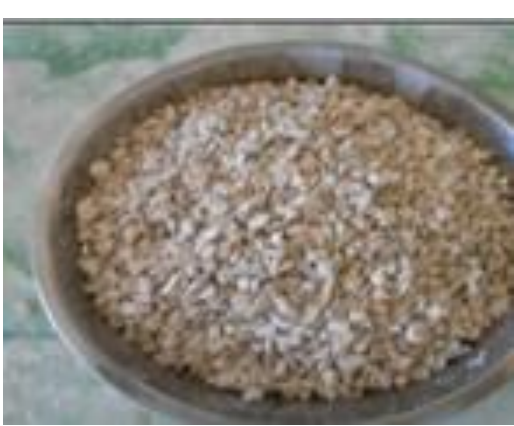

c $(\mathrm{G})$

Fig. (1). Aggregates used.

The dune sand was used to correct the fine part of the alluvial sand [28]. The natural fines of DS are very useful to improve the compactness of the MEPC composite. For this reason, the mixture of alluvial - dune sand obtained, denoted as ADS, is well-graded, and its grading curve is continuous and fits into in the desired ranges (Fig. 2). Let us note that it was used for a predetermined AS/DS mass ratio equal to 1.7 after its verification [23]. The main physical properties of the used sands (AS, DS and ADS) are summarized in Table 1. The sand equivalent values show that the three types of sand are clean and perfectly suitable to obtain a concrete composition with high performance. The fineness modulus of ADS, equal to 2.28 , confirms its better finesse compared to other sands. The results of the XRD analysis confirm the essentially siliceous nature of the used sands (Fig. 3); however, the AS contains some traces of calcite.

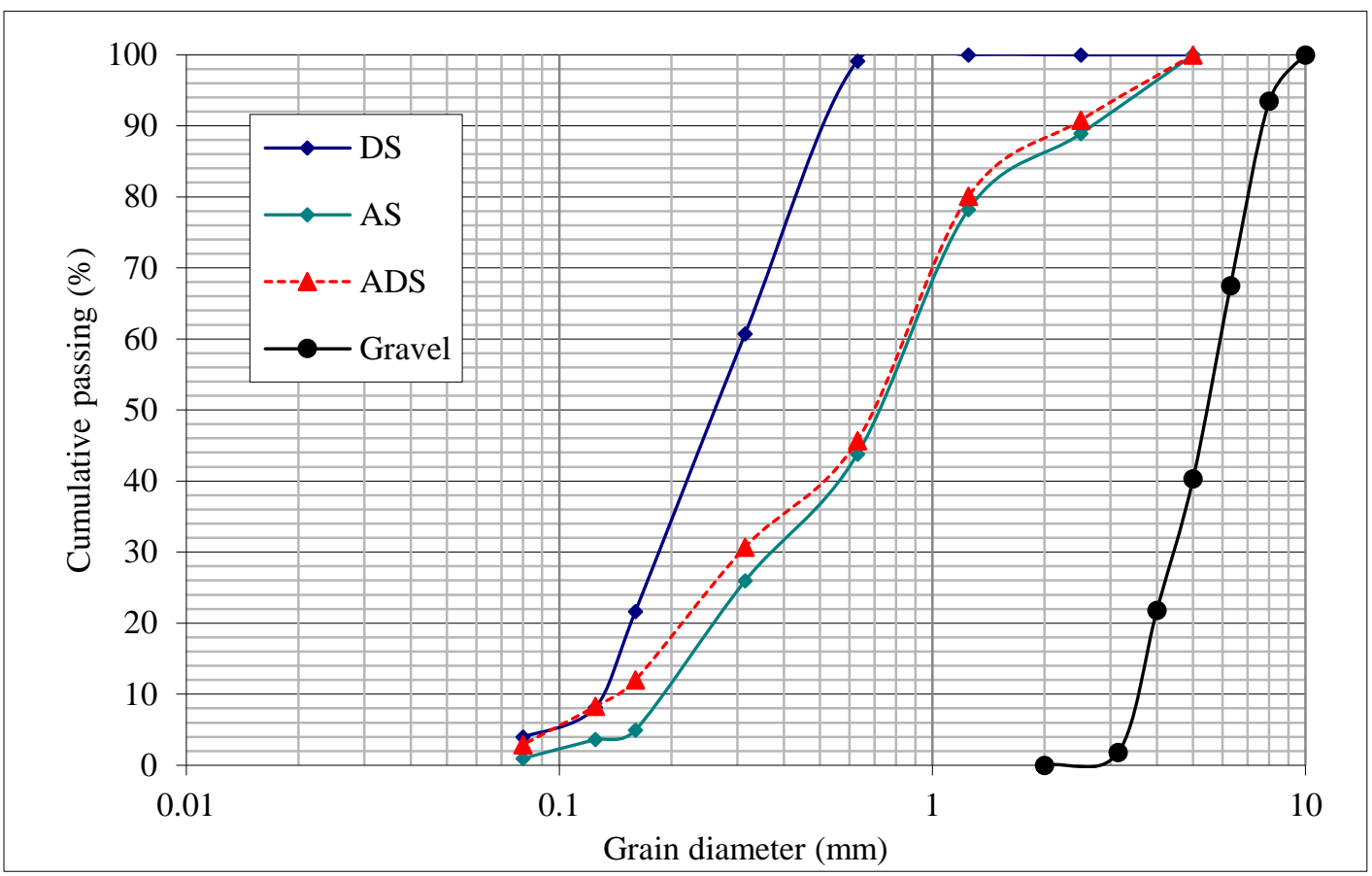

Fig. (2). The particle size distribution of the different aggregates used.

Table 1. Main physical properties of different sands used.

\begin{tabular}{|c|c|c|c|}
\hline Physical Characteristic & AS & DS & ADS \\
\hline Apparent density $\left(\mathrm{kg} / \mathrm{m}^{3}\right)$ & 1482 & 1428 & 1511 \\
\hline Specific density $\left(\mathrm{kg} / \mathrm{m}^{3}\right)$ & 2576 & 2596 & 2583 \\
\hline
\end{tabular}


(Table $\square$ ) contd.....

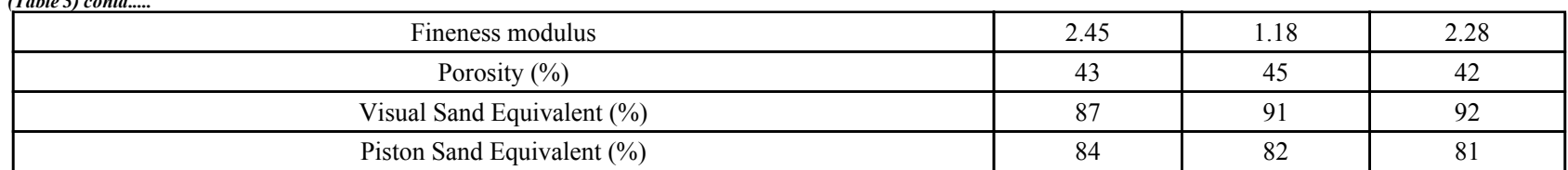

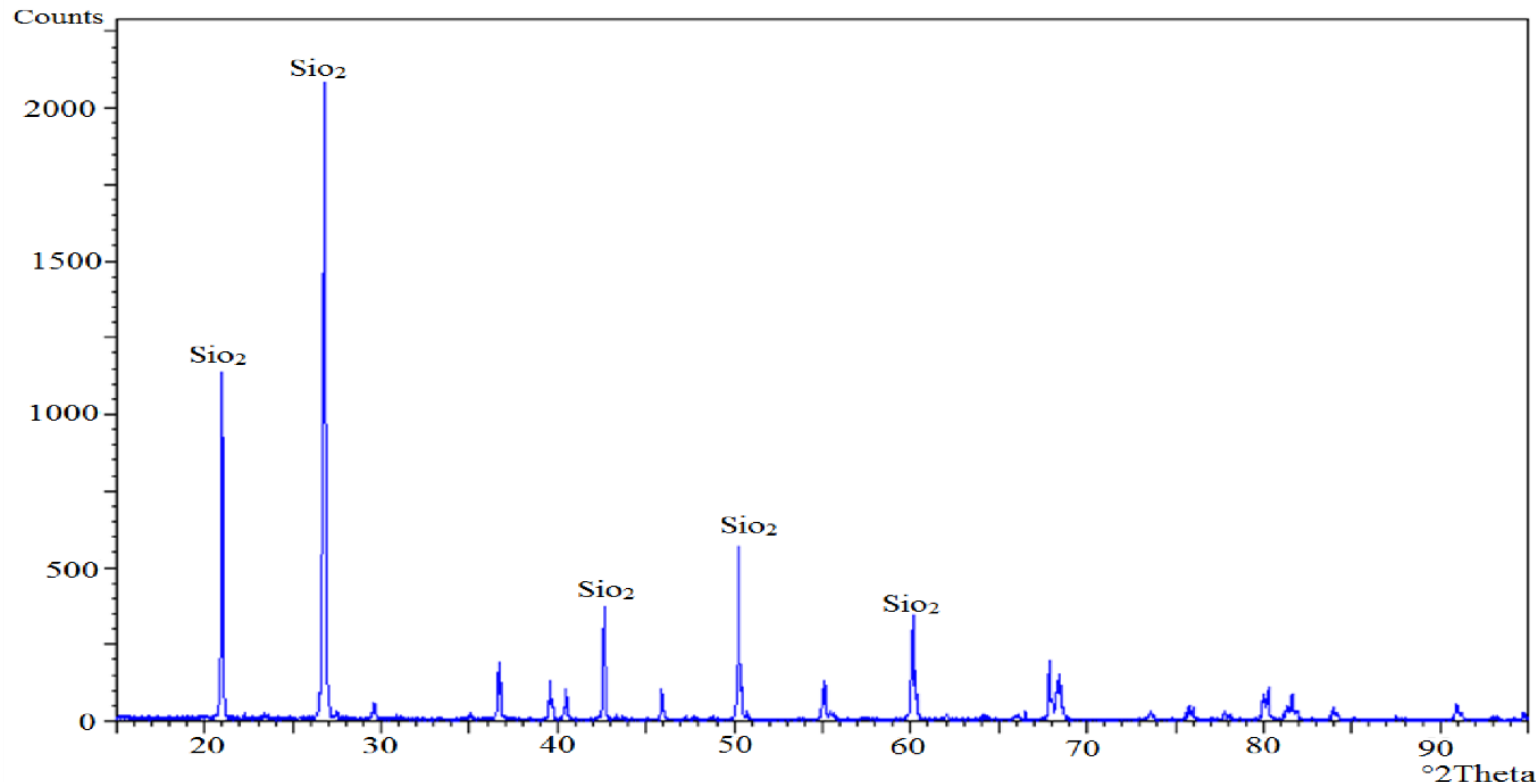

a (DS)

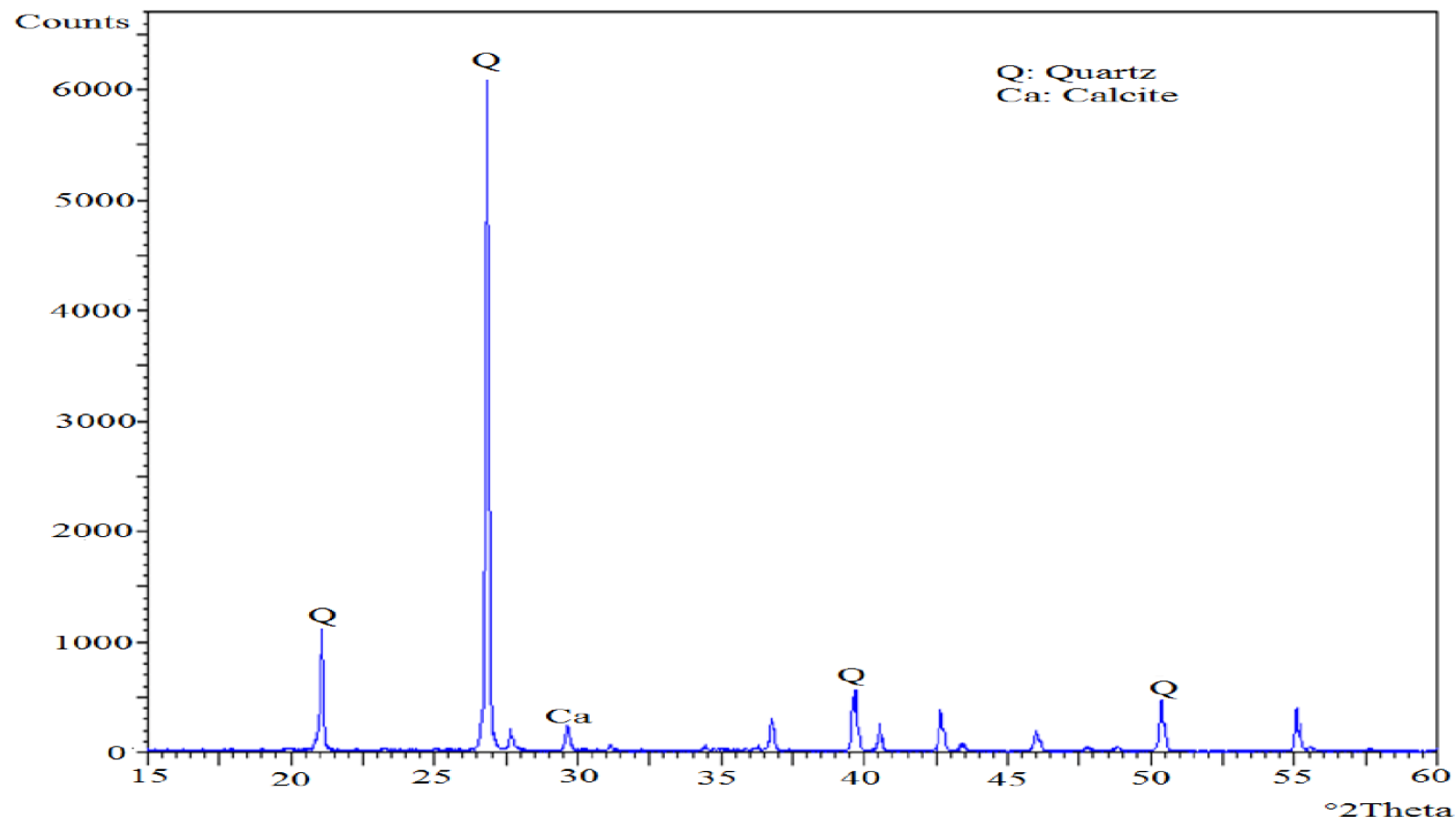

b (AS)

Fig. (3). XRD analysis of used sands. 
Table 2. Characteristics of epoxy resin used.

\begin{tabular}{|c|c|}
\hline Characteristic & Value \\
\hline Density & $1.1 \pm 0.05 \mathrm{~g} / \mathrm{cm}^{3}$ \\
\hline Viscosity at $25^{\circ} \mathrm{C}$ & $11000 \mathrm{MPa} . \mathrm{s}$ \\
\hline Curing time at $20^{\circ} \mathrm{C}$ and $65 \% \mathrm{HR}$ & $16 \mathrm{~h}$ \\
\hline Usual practice time (NFP18 810) & $1 \mathrm{~h} 15 \mathrm{~min}$ \\
\hline Compressive strength & $>70 \mathrm{MPa}$ \\
\hline Flexural strength & $>25 \mathrm{MPa}$ \\
\hline Adhesion on concrete & $>3 \mathrm{MPa}$ \\
\hline
\end{tabular}

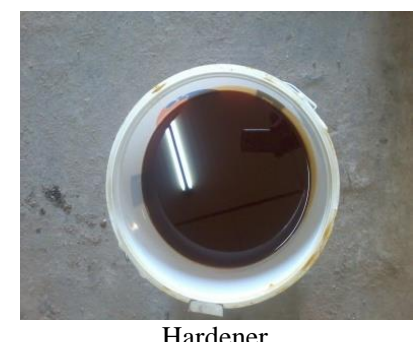

Hardener

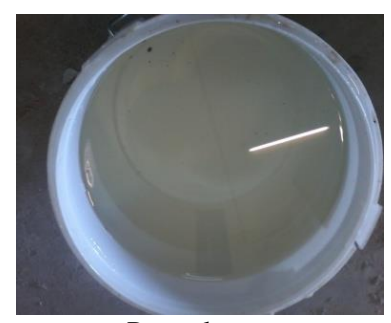

Pre-polymer

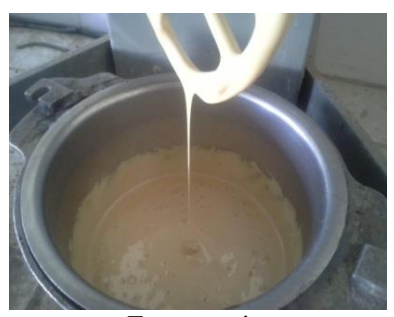

Epoxy resin

a)

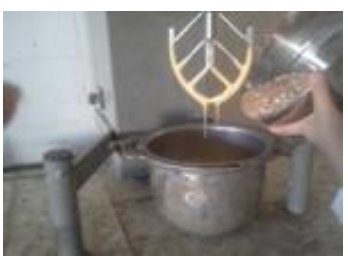

Introduction of aggregates

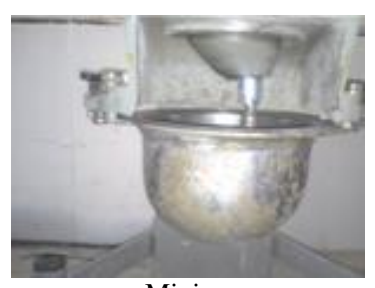

Mixing

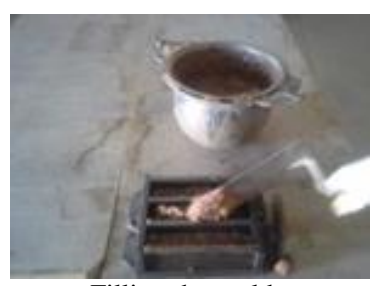

Filling the molds

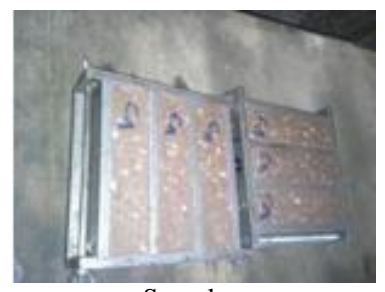

Samples

b)

Fig. (4). Mixing process of epoxy resin and MEPC composites.

A crushed limestone gravel $(\mathrm{G})$ of size range $3 / 8 \mathrm{~mm}$ (Fig.1c), extracted from a crushing plant in Laghouat, was used as a coarse aggregate. Its bulk and absolute densities are 1.42 and 2.66, respectively, its Los Angeles coefficient (LA) is $21 \%$ and its absorption rate is $1.07 \%$. The grading curve of this gravel is presented in Fig. (2). In order to obtain good adhesion between the PC components, all the used aggregates have been dried at $100 \pm 5^{\circ} \mathrm{C}$ for $24 \mathrm{~h}$, before being mixed with epoxy resin [29]. The combined angularity and surface texture properties of this gravel created a strong bond with the epoxy matrix and therefore improved the mechanical properties of the concrete [30].

\subsubsection{Polymer}

In this study, the polymer used is an epoxy resin whose trade name is "MEDAPOXY STR" from the Algerian Granitex company. This epoxy mixture is obtained by an epoxy resin prepolymer (part A) / hardener (part B) weight ratio of $3 / 2$, according to the manufacturer's recommendations. The characteristics of the epoxy used, according to the supplier's technical sheet, are noted in Table 2.

\subsubsection{Sample Preparation}

The mixing process of the studied MEPC was performed using a mortar mixer with 5 liters capacity. It should be noted that the preparation mode of MEPC is similar to that of concrete based on ordinary cement, but the curing mode is different [7].

First, the prepolymer (part A) and the hardener (part B) were sufficiently mixed for 3 minutes to achieve a perfectly homogeneous mixture (Fig. 4a) [30,31]. Then, the aggregates, previously dry-mixed, were gradually added to the epoxy binder for 3 minutes at low speed to ensure that all the aggregates were completely covered with epoxy resin. Immediately after mixing, $4 \times 4 \times 16 \mathrm{~cm}^{3}$ molds were filled in three equal layers and carefully compacted [31 - 34]. The latter were placed in the laboratory ambient conditions $\left(23 \pm 2^{\circ} \mathrm{C}\right.$ and $50 \pm 10 \%$ RH). Finally, the demolding was carried out after $24 \mathrm{~h}$ and the MEPC specimens were cured in the same conditions $\left(23 \pm 2^{\circ} \mathrm{C}\right.$ and $\left.50 \pm 10 \% \mathrm{RH}\right)$ until the corresponding test time.

The two epoxy resin contents $(10 \%$ and $14 \%)$ were selected for this study. This choice was based on a study of tensile and compressive strengths at 7 days of mortars samples, without gravel $3 / 8 \mathrm{~mm}$, produced with different epoxy 
contents, by taking into account all the other parameters approved in the preparation of studied MEPC composites such as the $\mathrm{AD} / \mathrm{DS}$ ratio $=1.7$. The results obtained revealed that the optimum epoxy content that leads to the best mechanical strengths ranges between $10 \%$ and $14 \%$. The tensile and compressive strengths at 7 days ranged from 16.6 to $19.5 \mathrm{MPa}$ and from 45.1 to $55.5 \mathrm{MPa}$, respectively. It should be noted that, at 7 days, epoxy polymer systems commonly achieved about $90 \%$ of their 28 -day strength [35]. Table 3 shows the mixture design for the selected MEPC composites.

\subsection{Experimental Investigation}

\subsubsection{Physical Tests}

The density of PC composites is an essential property, especially in the case of repair and reinforcement applications [30]. In this work, the variation of the density of MEPC samples as a function of $\mathrm{G} / \mathrm{S}$ ratio and epoxy content was followed during the first 28 days by the weight measurement of the studied samples, using a digital precision balance, with $0.1 \mathrm{~g}$ resolution. Each measurement was repeated at least three times.

In order to study the water absorption ratios of MEPC composites, $4 \times 4 \times 16 \mathrm{~cm}^{3}$ prismatic specimens, at 28 days of age, were dried in an oven at a temperature of $105 \pm 5^{\circ} \mathrm{C}$ until obtaining a constant weight (initial weight). Then, they were entirely immersed in water for $24 \mathrm{~h}$, then removed and weighed (final weight) after wiping the surface water of each sample with a dry cloth. The water absorption capacity (in mass) is reported as a percentage of the absorbed water in the dry samples. This value is taken as the average of the three measurements for each composition.

\subsubsection{Mechanical Tests}

Flexural and compressive strength tests of MEPC composites were carried out in accordance with standard NF EN 196-1 [36], at various ages: 1, 7, 28, 90 and 180 days. The flexural strength was examined by the three-point bending test on three prismatic specimens $\left(4 \times 4 \times 16 \mathrm{~cm}^{3}\right)$ for each mixture. The six half-test pieces resulting from the flexural test were then used to measure the compressive strength. A universal testing machine with a capacity equal to $100 \mathrm{kN}$ was used to perform these mechanical tests. The applied loads have constant speeds of $50 \mathrm{~N} / \mathrm{s}$ and $2500 \mathrm{~N} / \mathrm{s}$ for flexural and compression tests, respectively.

\subsubsection{Thermal Tests}

The thermal characteristics studied of MEPC are thermal conductivity, thermal diffusivity and specific heat. These tests are carried out on pairs of prismatic specimens of $4 \times 4 \times 8 \mathrm{~cm}^{3}$ at 28 days of age. The method used to determine these thermal properties is based on the principle of the Transient Plane Source (TPS) technique using the "Hot Disk TPS 500" device. The used software includes tools for automatic measurement and control of the temperature of external devices as well as tools for exporting the results to the microcomputer (Fig. 5a). The test was carried out using a small probe placed between two samples of the same composition (Fig.5b). Each measurement is relative to three similar tests.

\subsubsection{Structure Analysis}

Finally, the structure analysis of the studied composites was conducted on the macroscopic observation of the distribution of aggregates in the epoxy matrix and the aggregate-matrix contact zone. This analysis was made on the fractured faces of MEPCs using a Zeiss optical microscope (Stemi 2000-C, Germany) at $16 \times, 32 \times$ and $50 \times$ magnification.

\section{RESULTS AND DISCUSSION}

\subsection{Density}

First of all, the daily monitoring of the dry density variation of MEPC samples studied during the first 28 days showed a very slight change in the density over time. This may be due to the increased cross-linking density of the epoxy binder [3]. Fig. (6) shows the average dry densities of MEPC samples obtained at 28 days.

From Fig. (6), it was found that the density of MEPCs increased by increasing the G/S ratio. However, this increase in density differs according to the amount of epoxy resin: the rate of increase reaches about $6 \%$, for MEPCs containing $10 \%$ of epoxy, when the $\mathrm{G} / \mathrm{S}$ ratio varies from 0.25 to 0.75 . This is likely due to the use of coarse aggregates, which reduce the large pores by producing a high-density MEPC [37]. On the other hand, the effect of G/S ratio on the density of MEPCs, which contain $14 \%$ of epoxy is limited; the rate of density increase does not exceed $0.7 \%$ when the $\mathrm{G} / \mathrm{S}$ ratio changes from 0,25 to 0.75 .

Moreover, the approximate density values of MEPCs made with $14 \%$ of epoxy showed that this epoxy content is the optimal content, which is necessary to almost completely fill the voids between aggregates. This remark is in accordance with the results of Haidar et al. [8], where they found, for a fixed $\mathrm{G} / \mathrm{S}$ ratio equal to 0.25 , a slight increase in the density of MPC with the increase in epoxy content. Elalaoui et al. [3], noted, for a constant $\mathrm{G} / \mathrm{S}$ ratio equal to 0.54 , a significant decrease in the density of PC as the epoxy content increased. The mixtures of $14 \%$ epoxy show density-growth rates of $7 \%$, $4 \%$ and $1 \%$ compared to those containing $10 \%$ epoxy for $\mathrm{G} / \mathrm{S}$ ratios of $0.25,0.5$ and 0.75 , respectively. Maherzi et al. [38], found that the optimal amount of epoxy (14\%) results in a maximum density of polymer mortars. It should also be noted that increasing the quantity of coarse aggregate limits the effect of epoxy percentage on the density of MEPC. Finally, the densest MEPC is obtained at a polymer content of $14 \%$ and a $\mathrm{G} / \mathrm{S}$ ratio $=0.75$. 


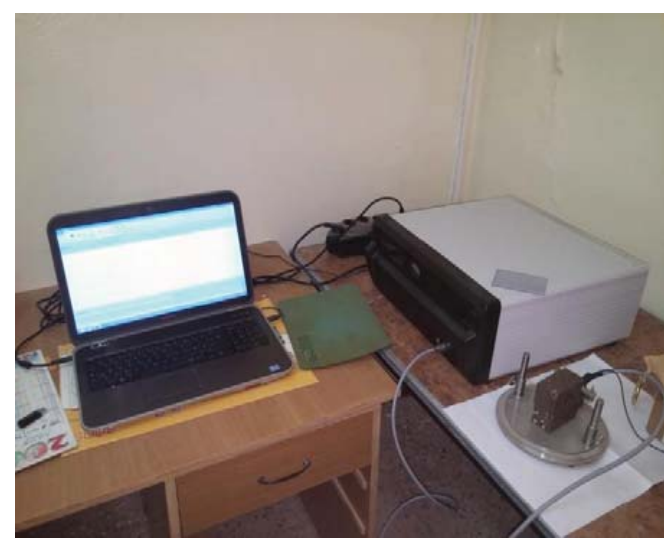

a)

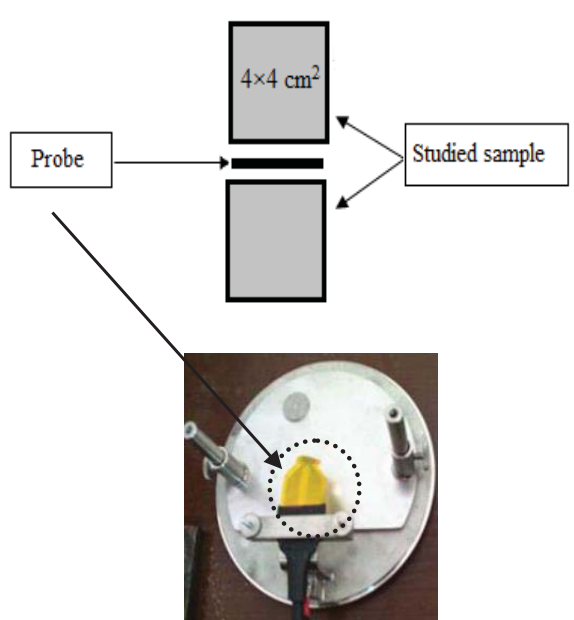

b)

Fig. (5). The device used for measurement of MEPC thermal properties.

Table 3. Mix proportions of selected MEPC composites.

\begin{tabular}{|c|c|c|c|c|c|}
\hline \multirow{2}{*}{ Designation } & \multirow{2}{*}{ Coarse Aggregates (\%) } & \multicolumn{2}{|c|}{ Fine Aggregates (\%) } & \multirow{2}{*}{ G/S } & \multirow{2}{*}{ Epoxy (\%) } \\
\cline { 3 - 5 } & & AS (\%) & DS (\%) & & \\
\hline MEPC10/0.25 & 18 & 45.33 & 26.67 & 0.25 & 10 \\
\hline MEPC10/0.5 & 30 & 37.78 & 22.22 & 0.5 & 10 \\
\hline MEPC10/0.75 & 38.57 & 32.38 & 19.05 & 0.75 & 10 \\
\hline MEPC14/0.25 & 17.2 & 43.32 & 25.48 & 0.25 & 14 \\
\hline MEPC14/0.5 & 28.67 & 36.10 & 21.23 & 0.5 & 14 \\
\hline MEPC14/0.75 & 36.86 & 30.94 & 18.2 & 0.75 & 14 \\
\hline
\end{tabular}

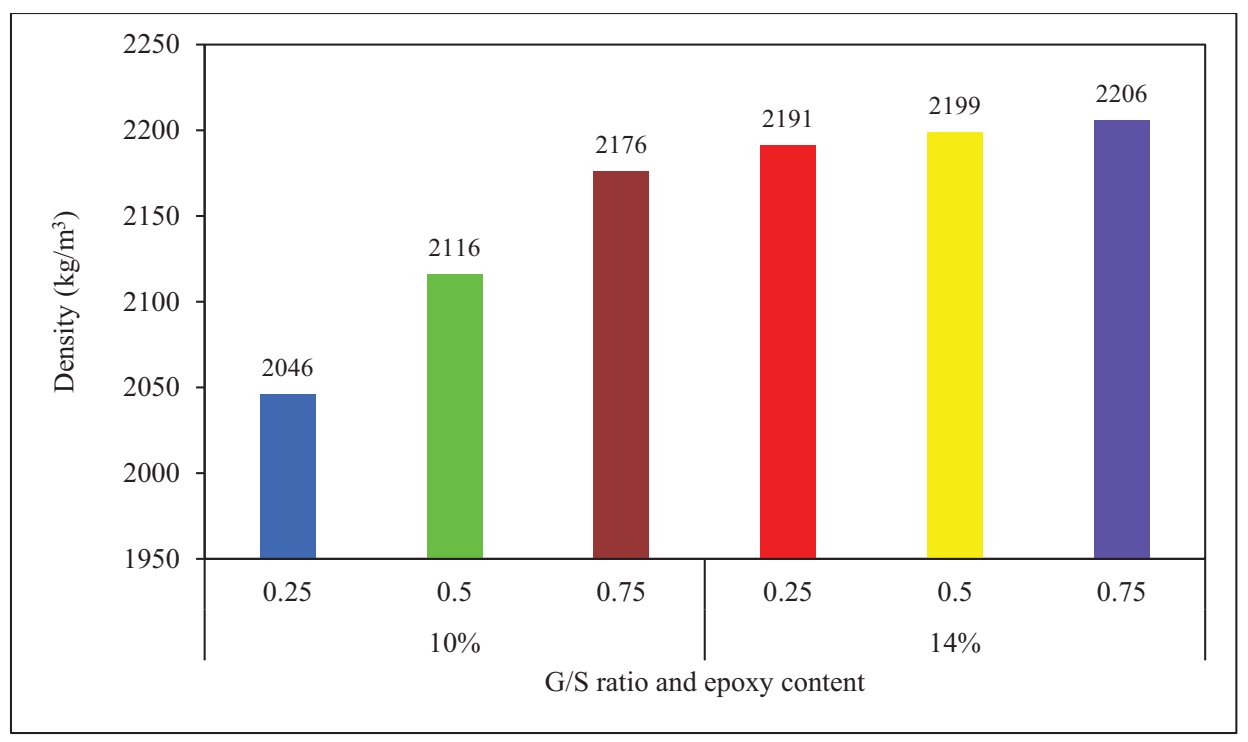

Fig. (6). Density variation of MEPC specimens at 28 days as a function of $\mathrm{G} / \mathrm{S}$ ratio and epoxy content. 


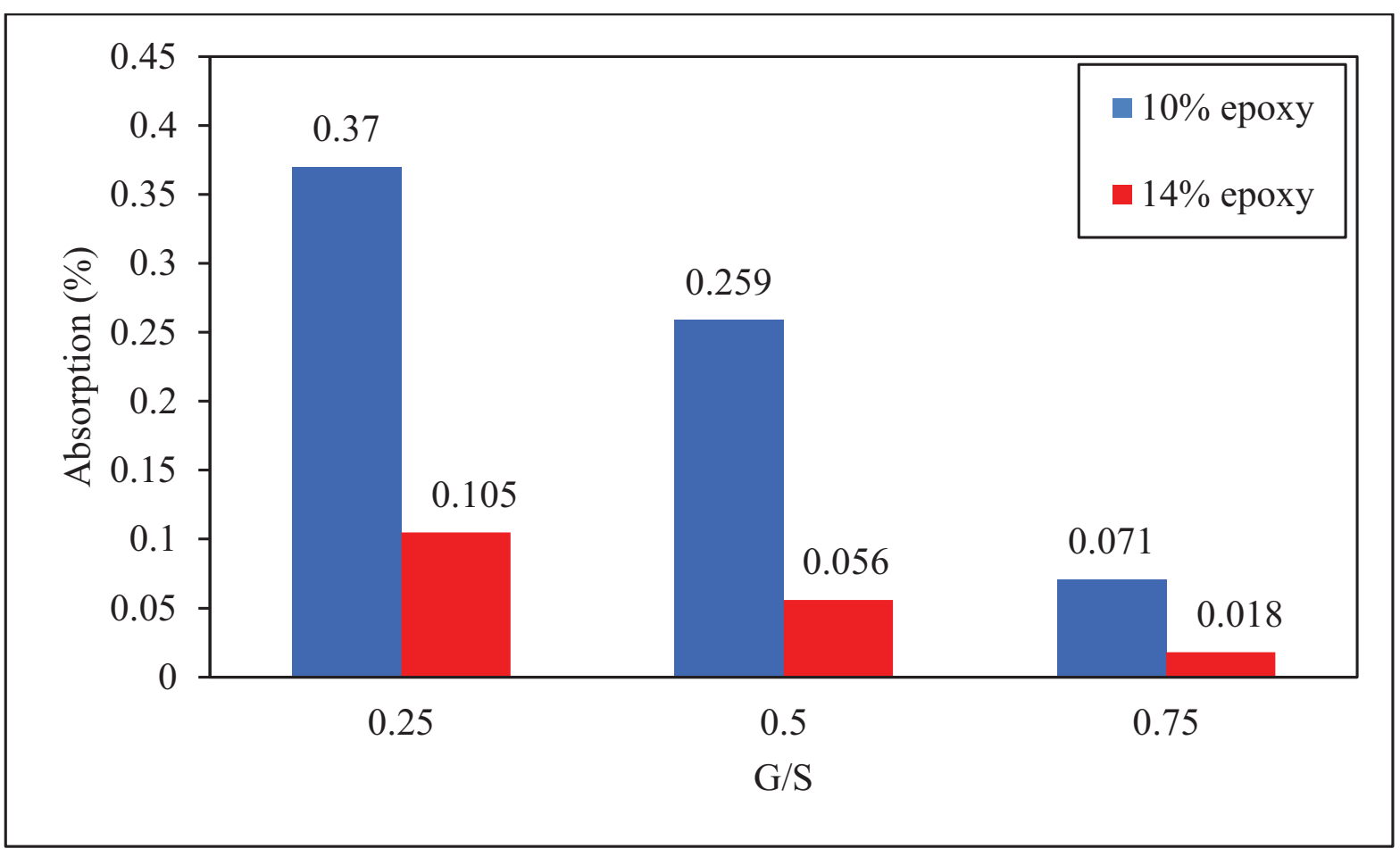

Fig. (7). Water absorption of studied MEPC.

\subsection{Water Absorption}

Fig. (7) shows the water absorption of the studied MEPC. The first point to be made is that all water absorption rates of MEPCs are very low and below $0.4 \%$, because of their high water-tightness $[4,39,40]$, and hydrophobic properties of hardened epoxy resins [4]. This desirable property indicates that MEPCs have better durability against adverse weather conditions as they can prevent the intrusion of water and salts $[1,41]$. In addition, the water absorption capacity of MEPCs decreases with the increase in $\mathrm{G} / \mathrm{S}$ ratio for the two epoxy contents $(10 \%$ and $14 \%)$, which confirms the decrease in the open porosity with increasing the G/S ratio. However, when the gravel ratio changes from 0.25 to 0.75 , the rate of decrease in water absorption of MEPCs for the two epoxy contents $(10 \%$ and $14 \%$ ) is almost identical and reaches $80 \%$.

Furthermore, the MEPCs produced with 14\% epoxy have very low water absorption rates, compared to those based on $10 \%$ of epoxy, regardless of the G/S ratio. This is due to the fact that all MEPCs with $14 \%$ of epoxy have fewer voids, due to the strong matrix-aggregate bond which prevents water penetration. Haidar et al. [8], discovered that the water absorption of MPC is at low levels for an epoxy content $\geq 9 \%$. The mixture MEPC10/0.25 shows a very high water absorption capacity than that of other mixtures. This is mainly due to the absence of coarse aggregates, which can make the mixture enough compact and the quantity of epoxy resin insufficient to wrap all aggregates and fill in all voids. However, the presence of coarse aggregates, in combination with the alluvial and dune sands, and an epoxy content of $14 \%$, show a synergy in the resistance to water absorption where the water absorption rate of mixture MEPC $14 / 0.75$ is practically too low $(0.018 \%)$.

The optical microscope images (at a magnification of $32 \times$ ) of the fracture surfaces of MEPCs, illustrated in Fig. (8), confirm the previous results (density and water absorption).

It can also be seen that the voids between aggregates and matrix are clearly reduced by increasing the amount of epoxy polymer. The pore diameters become smaller and the porosity is evenly distributed.

\subsection{Flexural strength}

The variation in the flexural strength of the studied MEPCs as a function of time is illustrated in Fig. (9). It is clear that the changes in epoxy resin content, G/S ratio and curing time cause a variation in the tensile strength of MEPCs. The flexural strength of the MEPCs obviously increases with the curing time: A rate of increase of $30 \%$ is reached between the first day and the seventh day, while a slight increase is recorded between the seventh day and the $180^{\text {th }}$ day. These increases are due to the cross-linking of the polymeric binder. In addition, it should be noted that all MEPCs have very significant flexural strength at the age of 1 day. 


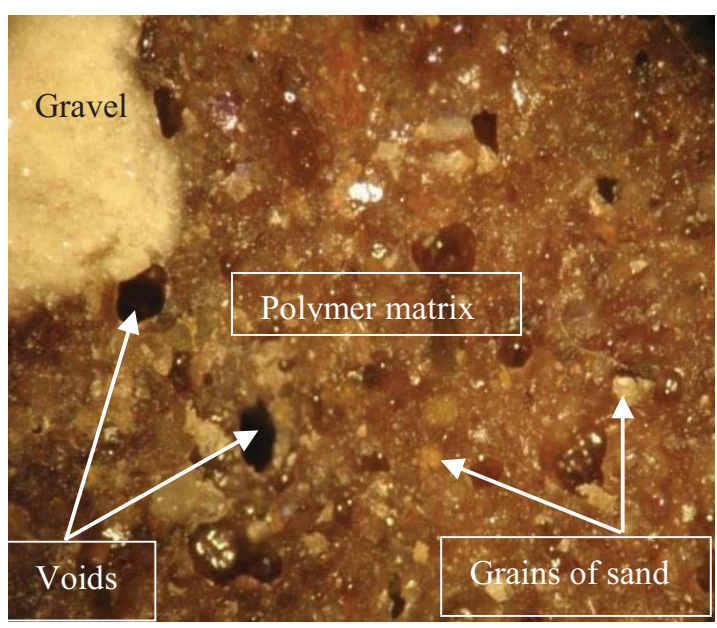

MEPC10/0.25

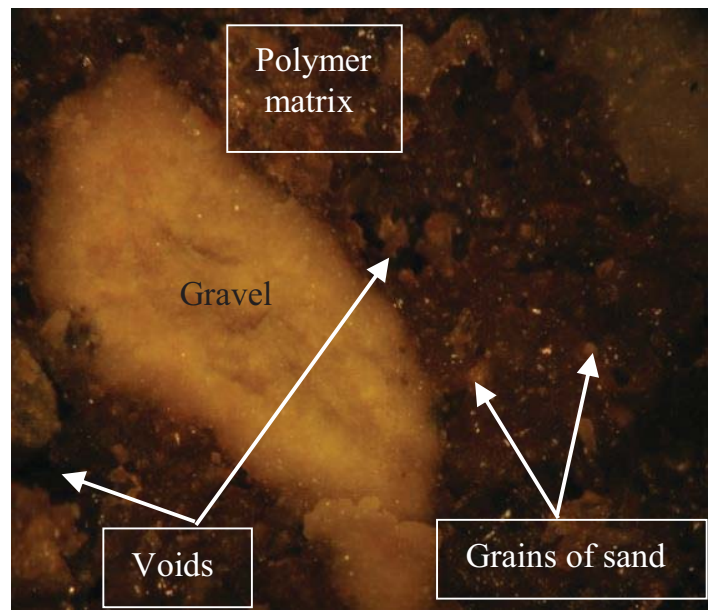

MEPC $10 / 0.5$

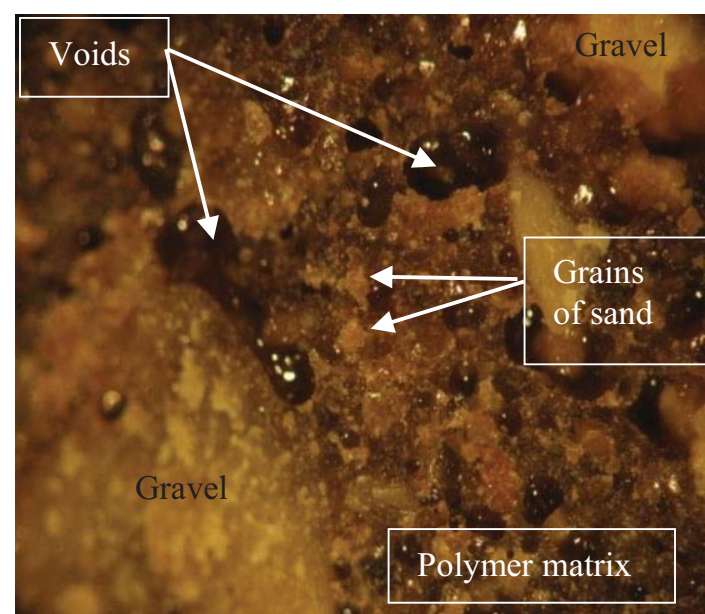

MEPC10/0.75

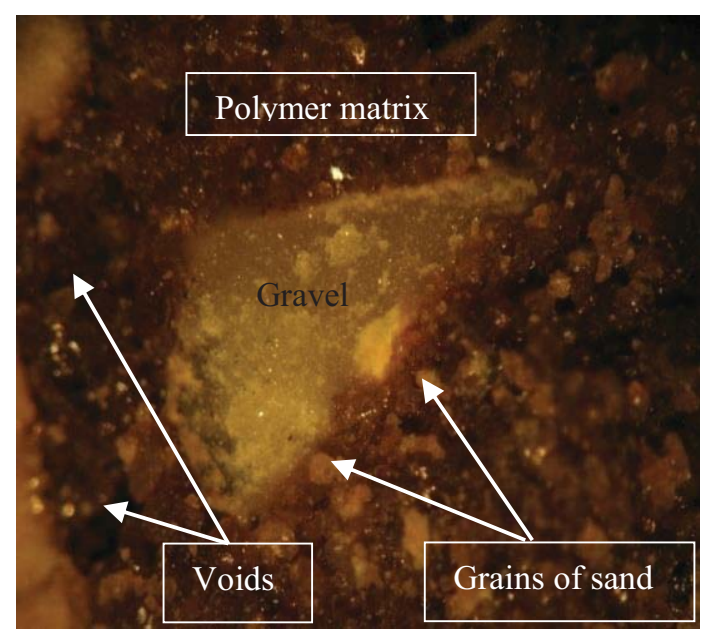

MEPC14/0.25

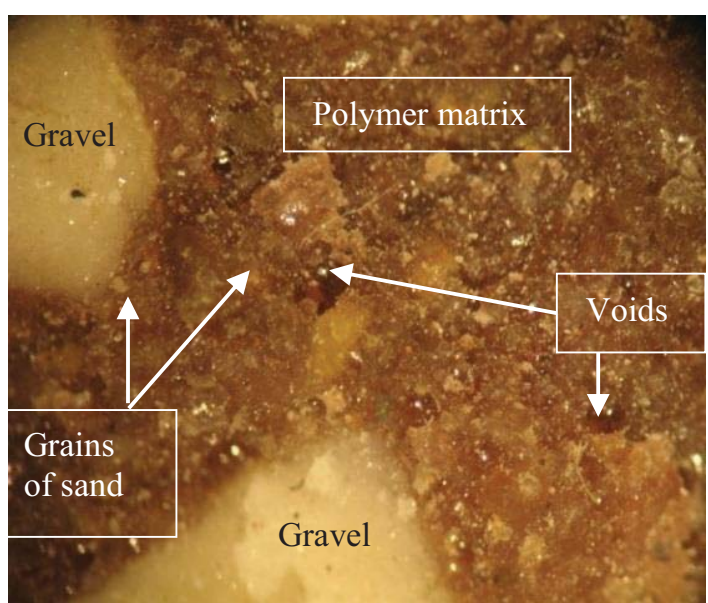

MEPC14/0.5

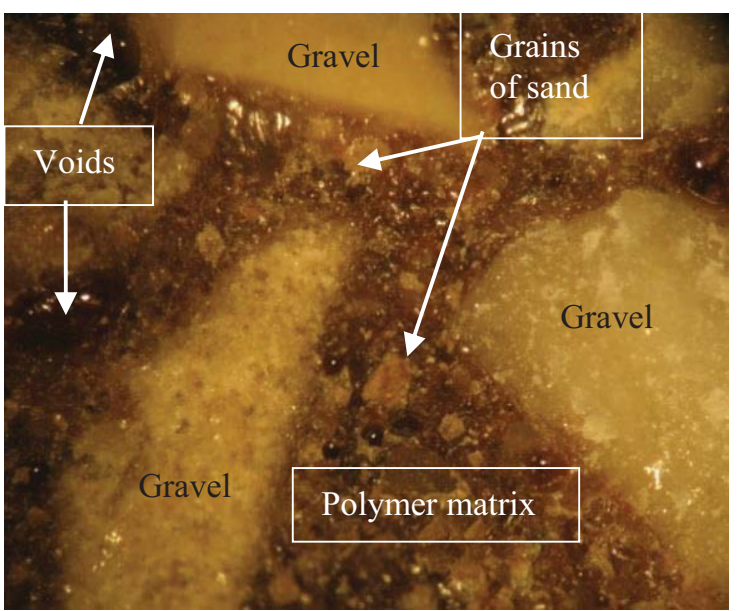

MEPC14/0.75

Fig. (8). Optical microscope images of the MEPC samples (32× magnification). 


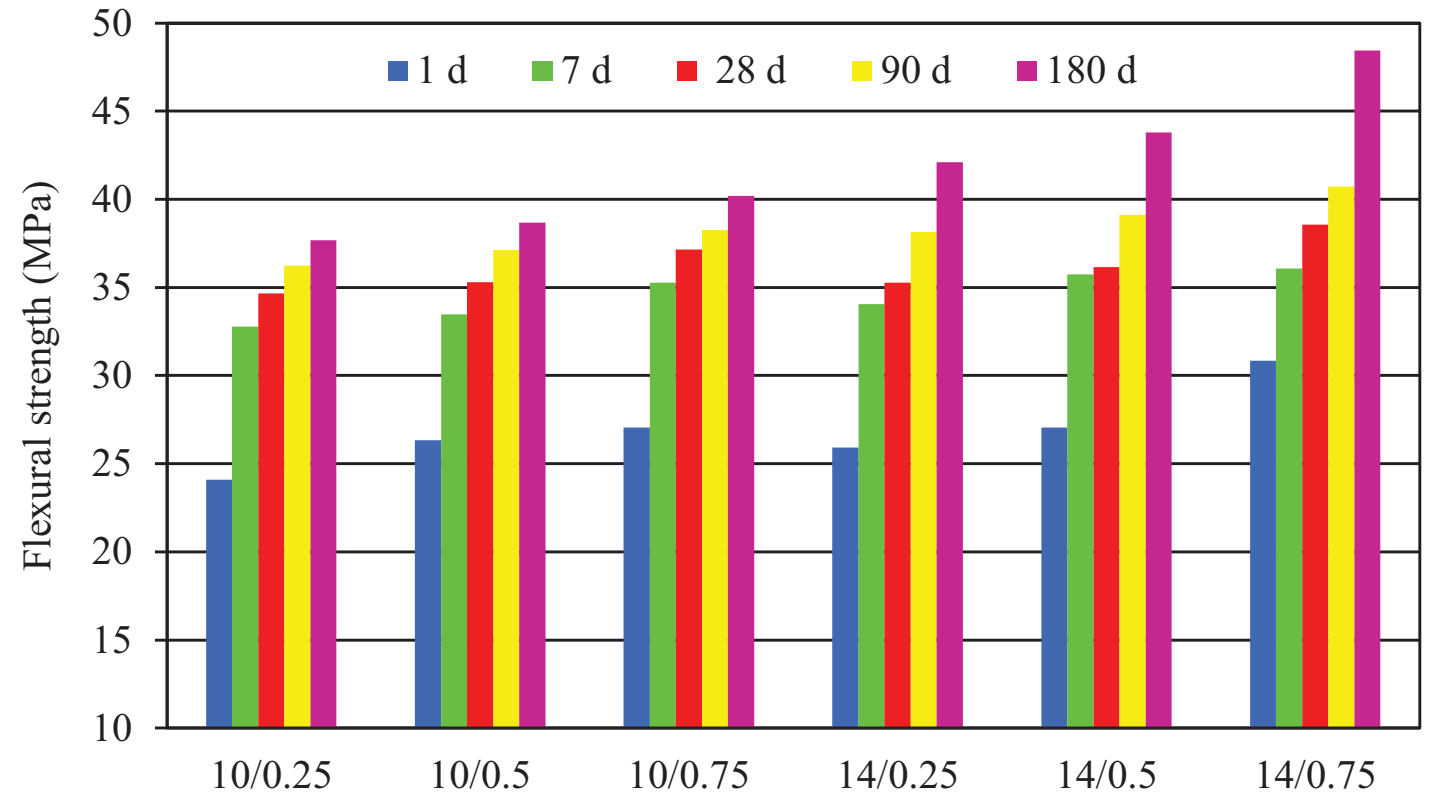

Type of MEPC

Fig. (9). Variation of flexural strength of MEPCs studied.

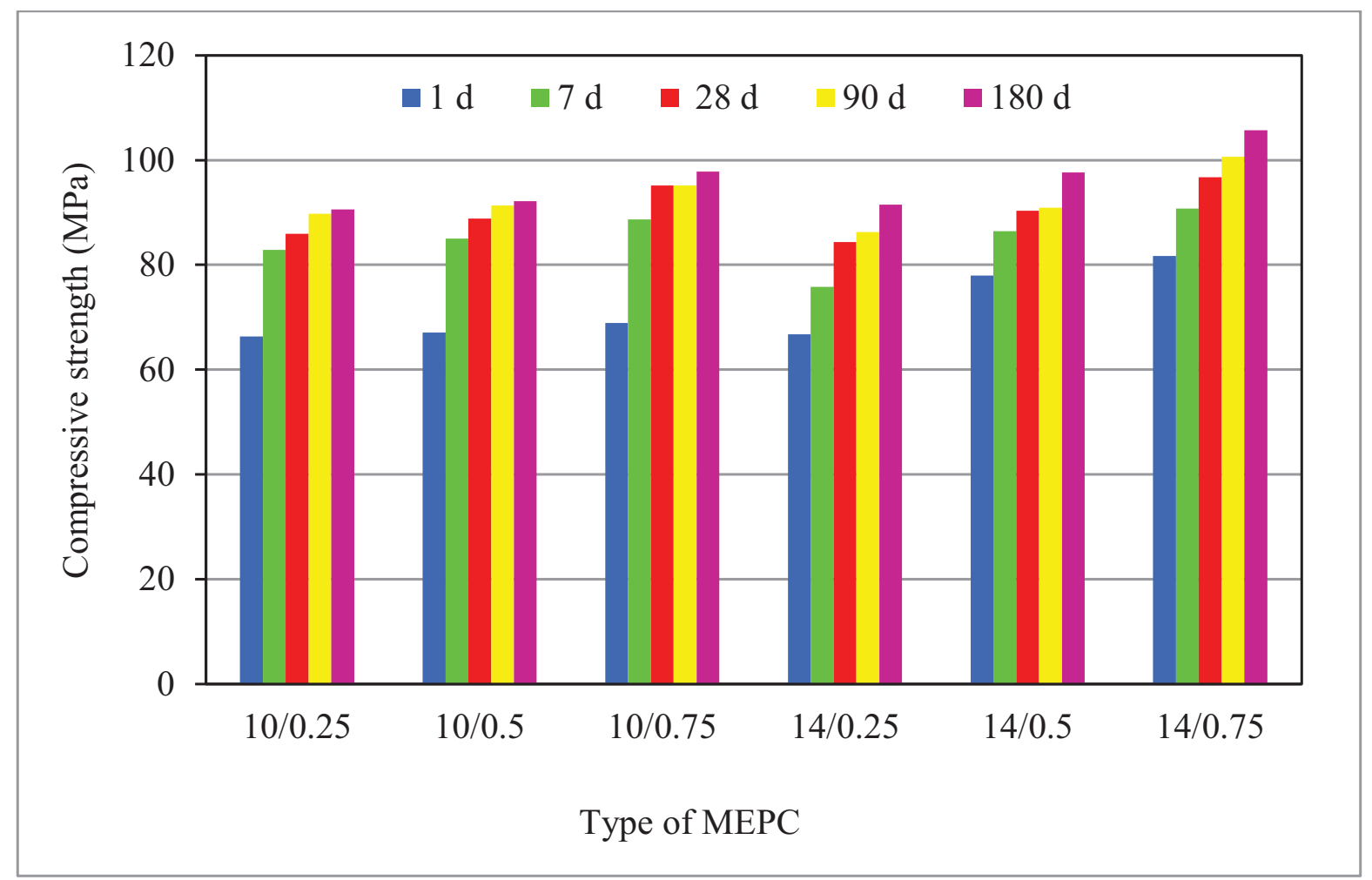

Fig.10. Variation of compressive strength of MEPCs studied. 
Regarding the effect of epoxy content on the flexural strength of MEPCs, the comparison between the two epoxy contents studied $(10 \%$ and $14 \%)$ for a constant $\mathrm{G} / \mathrm{S}$ ratio shows that this effect remains limited, especially when the mixture contains fine aggregates (low $\mathrm{G} / \mathrm{S}$ ratio) [5]. This can be attributed to the insufficient amount of epoxy resin to cover the sand particles [42]. Otherwise, the best flexural strengths were obtained for the MEPC with $14 \%$ of epoxy resin. This highlights the favorable effect of epoxy resin on the flexural strength of MEPC samples [5, 43]. On the other hand, when the $\mathrm{G} / \mathrm{S}$ ratio is increased, the flexural strength is improved. Therefore, the maximum value of the flexural strength is obtained for the MEPC14/0.75 mixture and is equal to $48.44 \mathrm{MPa}$ at 180 days. This result can be explained by the larger size of aggregates that decreases voids in the composite (makes it denser) and therefore, increases its flexural strength $[42,44]$. Preliminary experiments also confirm that the flexural strength of MEPCs is very high than that of polymer mortar for equal epoxy content. The addition of $3 / 8 \mathrm{~mm}$ gravel has a major effect on the flexural strength.

\subsection{Compressive Strength}

The results of the compression strength test of MEPCs are presented in Fig. (10). These results show a trend almost similar to that observed in the evolution of the flexural strength of MEPCs.

From Fig. (10), it is observed that the compressive strength evolved overtime for all MEPC mixtures. At 7 days, the compressive strength can reach more than $90 \%$ of the 180day compressive strength. This makes it easy to meet the application requirements for faster repair

$[15,35]$. In addition, it should be noted that the values of compression and flexural strengths obtained show that the MEPC composites are high-performance materials.

Furthermore, we can see that the compressive strengths slightly increased with the increase of the mass of epoxy resin, but the epoxy resin has a little effect on the compressive strength for $\mathrm{G} / \mathrm{S}=0.25$. The same remark has been observed for the influence of the $\mathrm{G} / \mathrm{S}$ ratio in the case of epoxy content equal to $10 \%$, where this effect was limited. Contrary to that, the increase in the percentage of coarse aggregates, for example, $\mathrm{G} / \mathrm{S}=14 \%$, contributes to obtaining a very high compressive strength. Consequently, the mixture MEPC0.75/14 has the best compressive strength at all ages and the maximum value of this resistance reaches $105 \mathrm{MPa}$ at 180 days. These values are higher than those obtained by Novoa et al. [45], who found a maximum compressive strength at 7 days equal to $68 \mathrm{MPa}$ for a percentage of $20 \%$ of epoxy resin and by Haidar et al. [8], who found compressive strengths between 23 and $70 \mathrm{MPa}$ for percentages of epoxy binder ranging from $5 \%$ to $13 \%$. These results are justified by the fact that the $\mathrm{G} / \mathrm{S}$ ratio of 0.75 increases the adhesion between the epoxy and the aggregates, which gives the MEPC of better quality. In addition, the amount of epoxy resin of $14 \%$ is sufficient to bind the grains and fill the intergranular voids.

\subsection{Thermal Properties}

The obtained results of the thermal tests, carried out on the different studied compositions are grouped in Table 4.

To quantify the influence of the G/S ratio and the epoxy content on the heat transfer potential, the thermal conductivity coefficient is calculated for each mixture. The thermal conductivity values of various MEPC composites are very low $[3,4,46]$; they are affected by the G/S ratio and the polymer content. The increase in the epoxy content decreases the total porosity and the average pore size by filling the voids of granular skeletons and by enveloping the aggregates. The heat transfer through the MEPC will, therefore, be attenuated and thus, a slight decrease in thermal conductivity will be recorded [3]. When the G/S ratio was increased, this decrease was significant: when the polymer content increased from $10 \%$ to $14 \%$, the rate decrease in thermal conductivity of $6 \%, 20 \%$ and $23 \%$ was recorded for the $\mathrm{G} / \mathrm{S}$ ratios of $0.25,0.5$ and 0.75 respectively. However, it should be noted that the thermal conductivity of MEPCs increases with increasing G/S ratio. It was concluded that the addition of mineral aggregates increased the conductivity of MEPCs [4]. But, this increase in conductivity, caused by coarse aggregates, differs depending on the epoxy content used. The effect of the $\mathrm{G} / \mathrm{S}$ ratio on the conductivity of MEPC mixtures with $10 \%$ of epoxy is clear, since the percentage increase reaches $26 \%$, while this percentage does not exceed 3\% in the case of MEPC mixtures with $14 \%$ of epoxy.

As indicated in Table 4, the thermal diffusivity values increase when the G/S ratio increases; a similar evolution has been observed for both MEPC with 10\% and MEPC with 14\% of epoxy. In addition, the values of thermal diffusivity range from 1.14 to $1.29\left(10^{-6} \times \mathrm{mm}^{2} / \mathrm{s}\right)$ in the case of $10 \%$ of epoxy and 0.89 and 1.19 in the case of $14 \%$ of epoxy, which show that the thermal diffusivity decreases with increasing epoxy content.

Table 4. Thermal properties of the studied MEPCs.

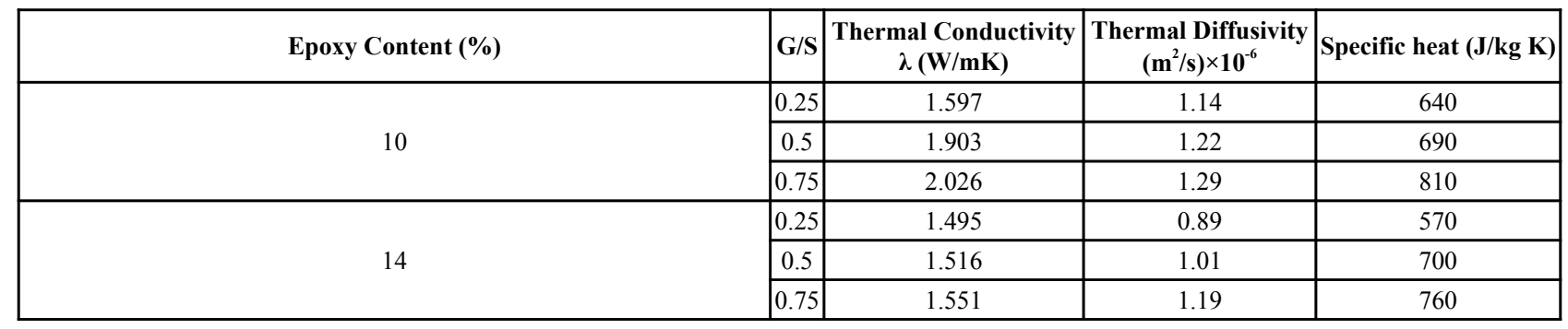


Regarding the specific heat, the obtained values were between 570 and $760(\mathrm{~J} / \mathrm{kg} \mathrm{K})$ for MEPCs based on $14 \%$ of epoxy and between 640 and $810(\mathrm{~J} / \mathrm{kg} \mathrm{K})$ for MEPCs of $10 \%$ of epoxy. These values indicate that the specific heat of MEPCs is increased when the coarser aggregates are added. In addition, increasing the epoxy content from $10 \%$ to $14 \%$ decreases the specific heat of MEPC. The same arguments used to justify the decrease in thermal conductivity are still valid for the thermal diffusivity and the specific heat.

\subsection{Macrostructure}

The optical microscope examination of the structure of the studied material was concentrated mainly on the general appearance of the composite, the morphology of the polymer paste, the matrix-aggregate adhesion and the distribution of aggregates in the matrix. The optical microscope images obtained are presented in Figs. (11 and 12).

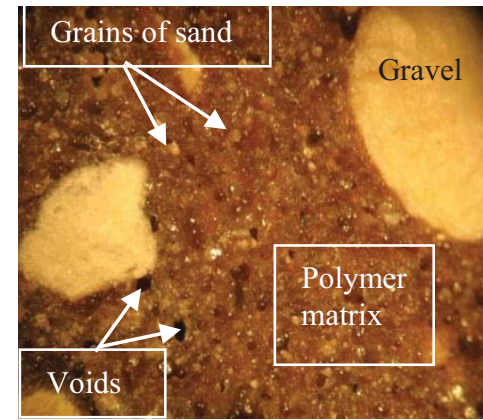

$\mathrm{G} / \mathrm{S}=0.25 ;(\mathrm{G}=16)$

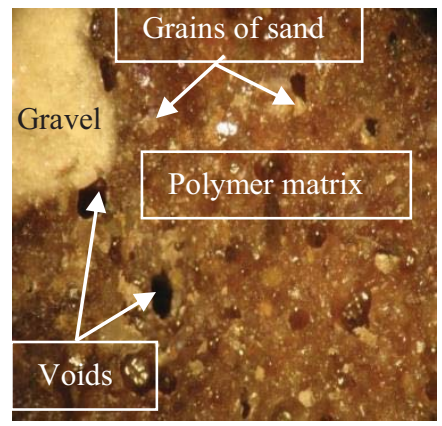

$\mathrm{G} / \mathrm{S}=0.25 ;(\mathrm{G}=32)$

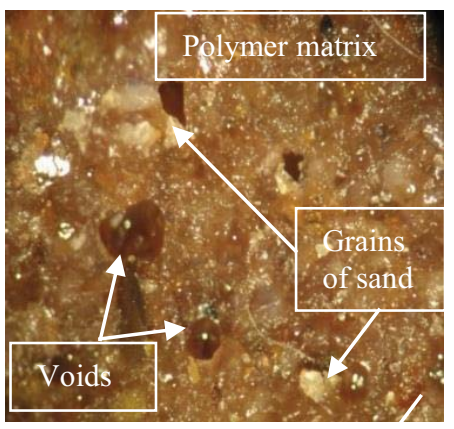

$\mathrm{G} / \mathrm{S}=0.25 ;(\mathrm{G}=50 ;$

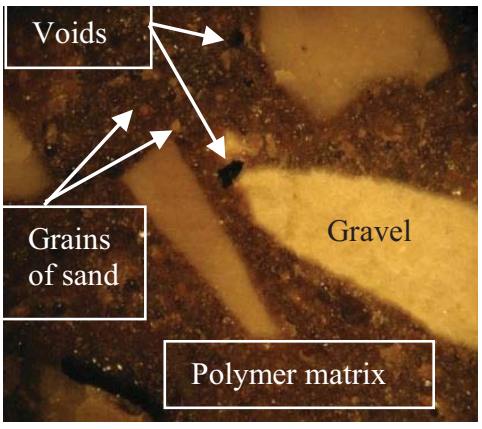

$\mathrm{G} / \mathrm{S}=0.5 ;(\mathrm{G}=16)$

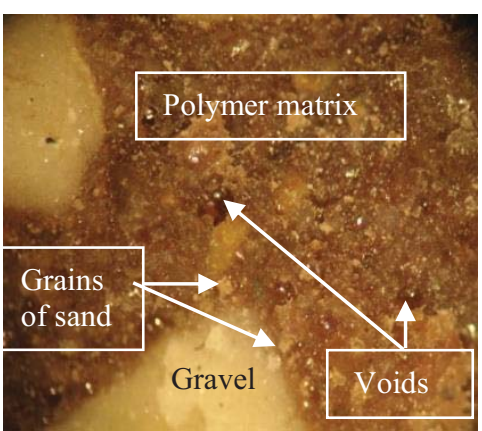

$\mathrm{G} / \mathrm{S}=0.5 ;(\mathrm{G}=32)$

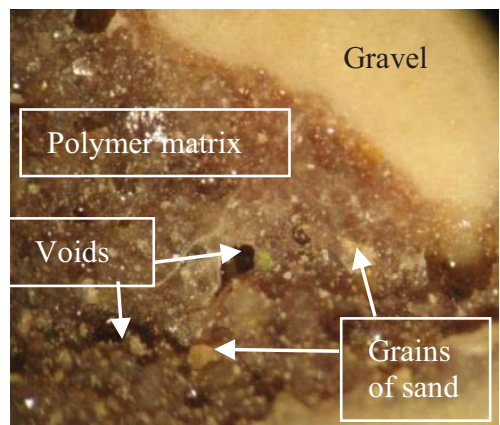

$\mathrm{G} / \mathrm{S}=0.5 ;(\mathrm{G}=50)$

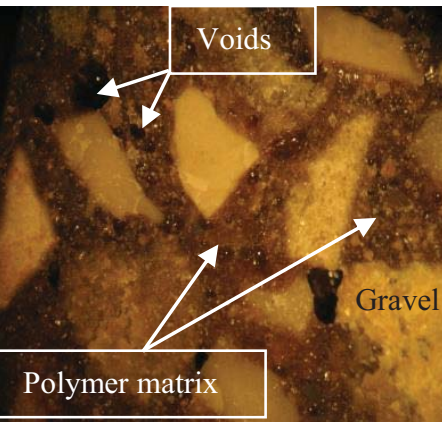

$$
\mathrm{G} / \mathrm{S}=0.75 ;(\mathrm{G}=16)
$$

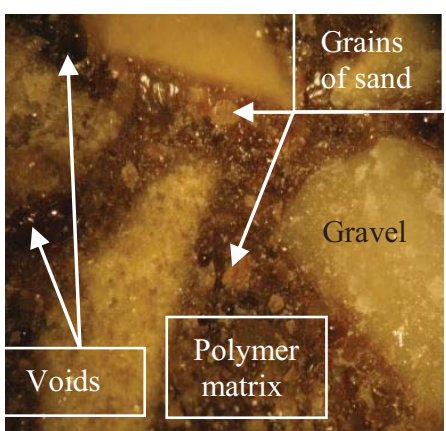

$$
\mathrm{G} / \mathrm{S}=0.5 ;(\mathrm{G}=32)
$$

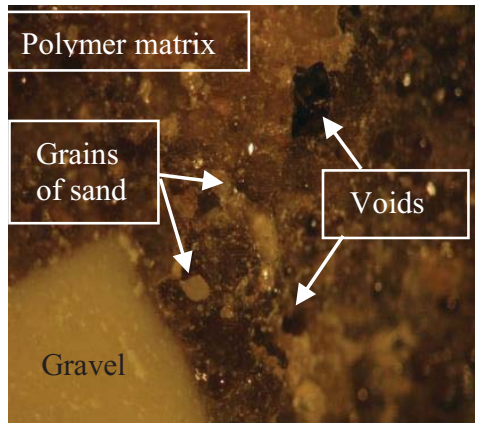

$\mathrm{G} / \mathrm{S}=0.75 ;(\mathrm{G}=50)$

Fig. (11). Optical microscope images of the MEPC14\% samples at magnifications of 16, 32 and 50 


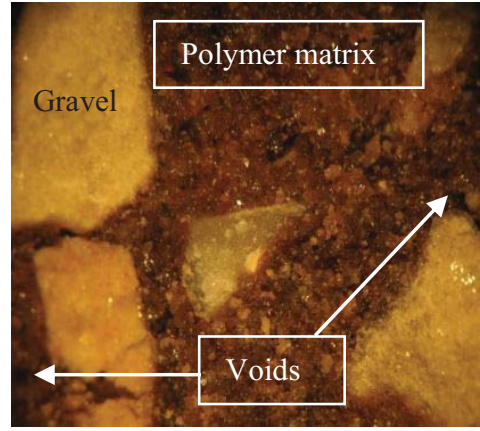

$\mathrm{G} / \mathrm{S}=0.25 ;(\mathrm{G}=16)$

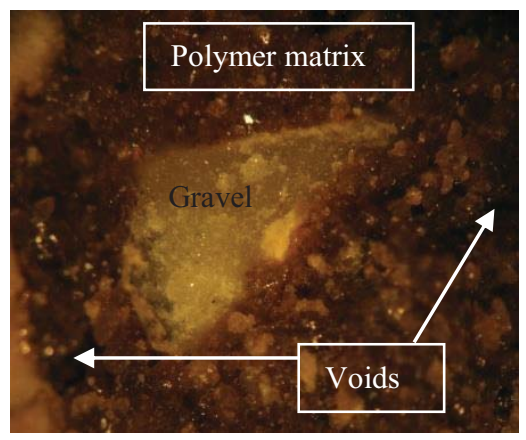

$\mathrm{G} / \mathrm{S}=0.25 ;(\mathrm{G}=32)$

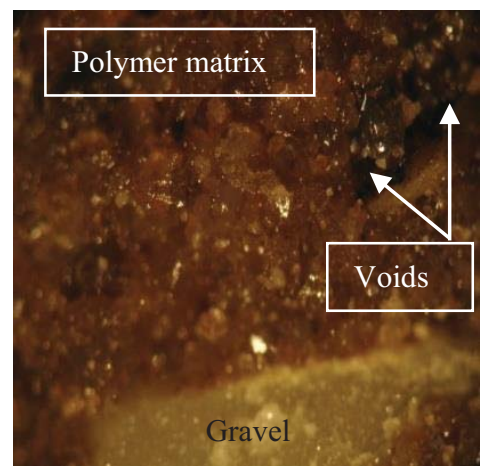

$\mathrm{G} / \mathrm{S}=0.25 ;(\mathrm{G}=50)$

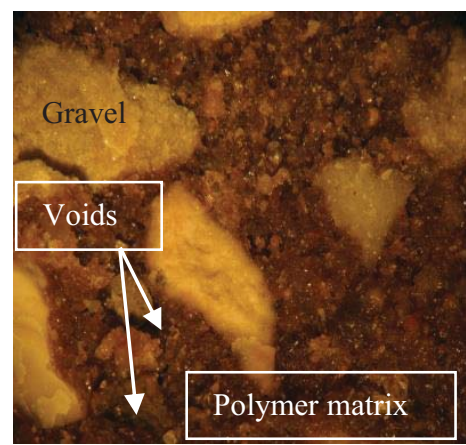

$\mathrm{G} / \mathrm{S}=0.5 ;(\mathrm{G}=16)$

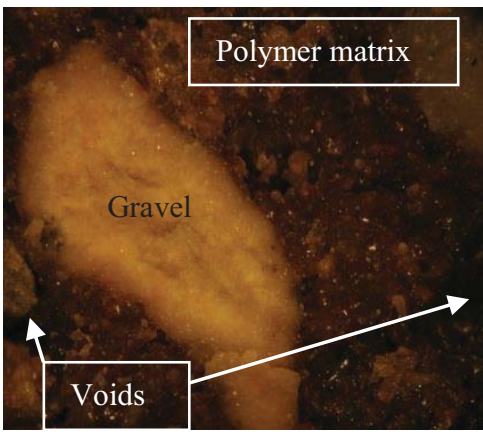

$\mathrm{G} / \mathrm{S}=0.5 ;(\mathrm{G}=32)$

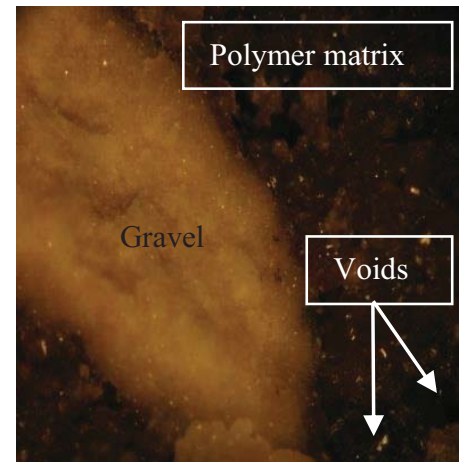

$\mathrm{G} / \mathrm{S}=0.5 ;(\mathrm{G}=50)$

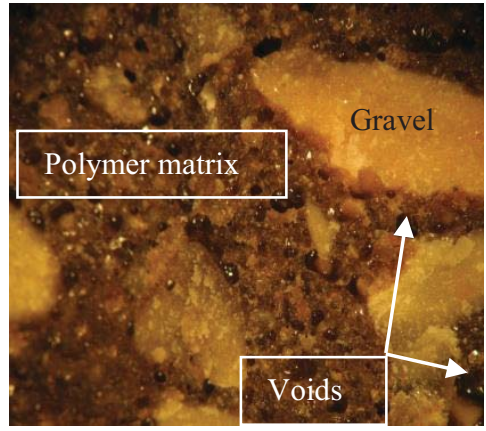

$\mathrm{G} / \mathrm{S}=0.75 ;(\mathrm{G}=16)$

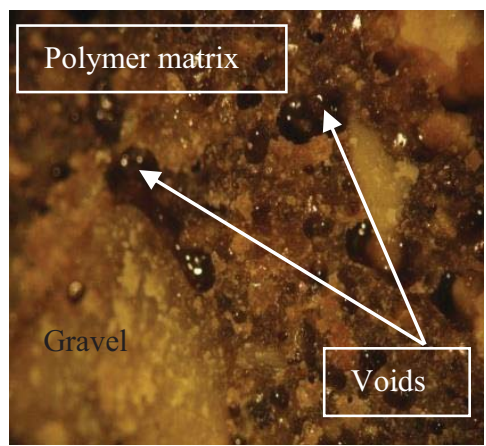

$\mathrm{G} / \mathrm{S}=0.75 ;(\mathrm{G}=32)$

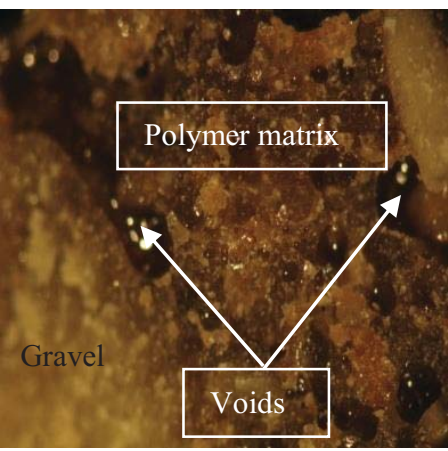

$\mathrm{G} / \mathrm{S}=0.75 ;(\mathrm{G}=50)$

Fig. (12). Optical microscope images of the MEPC14\% samples at magnifications of 16, 32 and 50.

The analysis by optical microscope of all the studied MEPC mixtures confirms that they have a continuous macrostructure with the absence of cracks and failures between aggregates and matrix. This shows that MEPCs can be considered as durable and more resistant building materials. In addition, the obtained images show the random distribution of coarse aggregates and porosity in the matrix. The pore distribution is different from one sample to another. It can be noted that the quantity and the size of the voids observed decrease with the increase in $\mathrm{G} / \mathrm{S}$ ratio. This finding confirms the increase in the density of MEPCs with the increase of G/S ratio. Compared to other mixtures, MEPC10-0.75 presents good aggregate-matrix adhesion, the sand grains are well coated by the paste and the aggregates are well distributed in the matrix.

From Figs. (11 and 12), it can be noted that the structure of MEPCs with $10 \%$ of epoxy seems to be less compact and less homogeneous than that of MEPCs with $14 \%$ of epoxy, which leads to more air bubbles due to their low polymer percentage. The general appearance of the matrix shows an increase in the porosity of the matrix when the percentage of the polymer decreases. This finding confirms the decrease in the density of MEPC with the decrease in polymer content, seen previously.

Finally, it should be noted that the density, the water absorption and the optical microscopic observation also 
confirms that mixes containing $14 \%$ epoxy are more impermeable than those containing $10 \%$ epoxy.

\section{CONCLUSION}

The study of the physico-mechanical, thermal and microstructural properties of MEPCs, prepared from local materials according to different $\mathrm{G} / \mathrm{S}$ ratios and epoxy contents, led to the following conclusions:

- The density of MEPCs increased with the increase of coarse aggregate content and epoxy content; consequently, the densest MEPC is obtained with a polymer content of $14 \%$ and a $\mathrm{G} / \mathrm{S}$ ratio of 0.75 .

- The water absorption coefficients of all MEPC mixtures indicate their high resistance to water absorption. In addition, the use of coarse aggregates in combination with alluvial and dune sands, in the case of an epoxy content of $14 \%$, leads practically to lower water absorption rate, which can reach $0.018 \%$.

- The best mechanical strengths obtained at an early age show that the studied MEPCs are high-performance building materials that can easily meet the application requirements for faster repair.

- The addition of coarse aggregates and the increase in the epoxy content increase the flexural and compressive strengths of the studied MEPCs. However, this improvement is reduced at low $\mathrm{G} / \mathrm{S}$ ratios.

- The reduced thermal conductivity of MEPCs, prepared with $14 \%$ of epoxy and containing coarse aggregates, can make it possible to obtain better thermal insulation performance.

- Optical microscopy images have shown that MEPCs present a dense and homogeneous macrostructure, especially when they contain coarse aggregates.

- Finally, the density, the water absorption and the optical microscopic observation also confirm that mixes containing $14 \%$ epoxy are more impermeable than those containing $10 \%$ epoxy.

\section{CONSENT FOR PUBLICATION}

Not applicable.

\section{AVAILABILITY OF DATA AND MATERIALS}

Not applicable.

\section{FUNDING}

None.

\section{CONFLICT OF INTEREST}

The authors declare no conflict of interest, financial or otherwise.

\section{ACKNOWLEDGEMENTS}

We would like to thank the General Directorate of Scientific Research and Technological Development of Algeria (DGRSDT) for their support.

\section{REFERENCES}

[1] W. Ferdous, A. Manalo, H.S. Wong, R. Abousnina, O.S. AlAjarmeh, Y. Zhuge, and P. Schubel, "Optimal design for epoxy polymer concrete based on mechanical properties and durability aspects", Constr. Build. Mater., vol. 232, 2020.117229 [http://dx.doi.org/10.1016/j.conbuildmat.2019.117229]

[2] C. Vipulanandan, and E. Paul, "Characterization of polyester polymer and polymer concrete", J. Mater. Civ. Eng., vol. 5, pp. 62-82, 1993. [http://dx.doi.org/10.1061/(ASCE)0899-1561(1993)5:1(62)]

[3] O. Elalaoui, E. Ghorbel, V. Mignot, and M. Ben Ouezdou, "Mechanical and physical properties of epoxy polymer concrete after exposure to temperatures up to $250^{\circ} \mathrm{C} "$, Constr. Build. Mater., vol. 27 , no. 1, pp. 415-424, 2012.

[http://dx.doi.org/10.1016/j.conbuildmat.2011.07.027]

[4] J. Wang, Q. Dai, S. Guo, and R. Si, "Mechanical and durability performance evaluation of crumb rubber-modified epoxy polymer concrete overlays", Constr. Build. Mater., vol. 203, pp. 469-480, 2019. [http://dx.doi.org/10.1016/j.conbuildmat.2019.01.085]

[5] W. Ferdous, A. Manalo, T. Aravinthan, and G. Van Erp, "Properties of epoxy polymer concrete matrix: Effect of resin-to-filler ratio and determination of optimal mix for composite railway sleepers", Constr. Build. Mater., vol. 124, pp. 287-300, 2016.

[http://dx.doi.org/10.1016/j.conbuildmat.2016.07.111]

[6] D. Ma, Y. Liu, N. Zhang, Z. Jiang, L. Tang, and H. Xi, "Micromechanical modeling of flexural strength for epoxy polymer concrete", Int. J. Appl. Mech., vol. 09, no. 08, 2017.1750117

[http://dx.doi.org/10.1142/S1758825117501174]

[7] P. Ghassemi, and V. Toufigh, "Durability of epoxy polymer and ordinary cement concrete in aggressive environments", Constr. Build. Mater., vol. 234, 2020.117887

[http://dx.doi.org/10.1016/j.conbuildmat.2019.117887]

[8] M. Haidar, E. Ghorbel, and H. Toutanji, "Optimization of the formulation of micro-polymer concretes", Constr. Build. Mater., vol. 25, no. 4, pp. 1632-1644, 2011.

[http://dx.doi.org/10.1016/j.conbuildmat.2010.10.010]

[9] J.M.L. Reis, and A.J.M. Ferreira, "The effects of atmospheric exposure on the fracture properties of polymer concrete", Build. Environ., vol. 41, no. 3, pp. 262-267, 2006.

[http://dx.doi.org/10.1016/j.buildenv.2004.12.017]

[10] K. Jafari, M. Tabatabaeian, A. Joshaghani, and T. Ozbakkaloglu, "Optimizing the mixture design of polymer concrete: An experimental investigation", Constr. Build. Mater., vol. 167, pp. 185-196, 2018. [http://dx.doi.org/10.1016/j.conbuildmat.2018.01.191]

[11] E. Kirlikovali, "Polymer/concrete composites - A review", Polym. Eng. Sci., vol. 21, pp. 507-509, 1981.

[http://dx.doi.org/10.1002/pen.760210811]

[12] M. Muthukumar, and D. Mohan, "Studies on polymer concretes based on optimized aggregate mix proportion", Eur. Polym. J., vol. 40, no. 9 , pp. 2167-2177, 2004.

[http://dx.doi.org/10.1016/j.eurpolymj.2004.05.004]

[13] R. Bedi, R. Chandra, and S.P. Singh, "Mechanical properties of polymer concrete", J. Compos., pp. 1-12, 2013.

[http://dx.doi.org/10.1155/2013/948745]

[14] Y. Shen, J. Huang, X. Ma, F. Hao, and J. Lv, "Experimental study on the free shrinkage of lightweight polymer concrete incorporating waste rubber powder and ceramsite", Compos. Struct., vol. 242, 2020.112152 [http://dx.doi.org/10.1016/j.compstruct.2020.112152]

[15] A. Bourguiba, E. Ghorbel, L. Cristofol, and W. Dhaoui, "Effects of recycled sand on the properties and durability of polymer and cement based mortars", Constr. Build. Mater., vol. 153, pp. 44-54, 2017. [http://dx.doi.org/10.1016/j.conbuildmat.2017.07.029]

[16] Y. Ohama, "Mix proportions and properties of polyester resin Concretes", Am. Concr. Inst. Spec. Publ., vol. 40, pp. 283-294, 1973.

[17] V. Kantha Rao, and S. Krishnamoothy, "Aggregate mixtures for leastvoid content for use in polymer concrete", Cem. Concr. Aggreg., vol. 15, no. 2, pp. 97-107, 1993.

[18] A. Shigang, T. Liqun, M. Yiqi, P. Yongmao, L. Yiping, and F. Daining, "Effect of aggregate distribution and shape on failure behavior of polyurethane polymer concrete under tension", Comput. Mater. Sci., vol. 67, pp. 133-139, 2013.

[http://dx.doi.org/10.1016/j.commatsci.2012.08.029]

[19] M.C.S. Ribeiro, P.R. Nóvoa, A.J.M. Ferreira, and A.T. Marques, "Flexural performance of polyester and epoxy polymer mortars under severe thermal conditions", Cement Concr. Compos., vol. 26, pp. 803-809, 2004.

[http://dx.doi.org/10.1016/S0958-9465(03)00162-8] 
[20] M.C.S. Ribeiro, C.M.L. Tavares, M. Figueiredo, A.J.M. Ferreira, and A.A. Fernandes, "Bending characteristics of resin concretes", Mater. Res., vol. 6, no. 2, pp. 247-254, 2003

[http://dx.doi.org/10.1590/S1516-14392003000200021]

[21] M.M. Shokrieh, M. Heidari-Rarani, M. Shakouri, and E. Kashizadeh, "Effects of thermal cycles on mechanical properties of an optimized polymer concrete", Constr. Build. Mater., vol. 25, no. 8, pp. 3540-3549, 2011.

[http://dx.doi.org/10.1016/j.conbuildmat.2011.03.047]

[22] P. Nogueira, C. Ramírez, A. Torres, M.J. Abad, J. Cano, J. López, I. López-Bueno, and L. Barral, "Effect of water sorption on the structure and mechanical properties of an epoxy resin system", J. Appl. Polym. Sci., vol. 80, no. 1, pp. 71-80, 2001.

[http://dx.doi.org/10.1002/1097-4628(20010404)80:1<71::AID-APP10 $77>3.0 . \mathrm{CO} ; 2-\mathrm{H}]$

[23] M. Bederina, M.M. Khenfer, R.M. Dheilly, and M. Quéneudec, "Reuse of local sand: effect of limestone filler proportion on the rheological and mechanical properties of different sand concretes", Cement Concr. Res., vol. 35, no. 6, pp. 1172-1179, 2005.

[http://dx.doi.org/10.1016/j.cemconres.2004.07.006]

[24] H. Berkak, M. Bederina, and Z. Makhloufi, "Physico-mechanical and microstructural properties of an eco-friendly limestone mortar modified with styrene-polyacrylic latex", J. Build. Eng., vol. 32, 2020.101463

[http://dx.doi.org/10.1016/j.jobe.2020.101463]

[25] A. Boucedra, M. Bederina, and Y. Ghernouti, "Study of the acoustical and thermo-mechanical properties of dune and river sand concretes containing recycled plastic aggregates", Constr. Build. Mater., vol. 256, 2020.119447

[http://dx.doi.org/10.1016/j.conbuildmat.2020.119447]

[26] M. Bederina, M. Hadjoudja, R.M. Dheilly, Z. Makhloufi, and M. Quéneudec, "Combined effect of sand grain size and contents of wood and filler on the physicomechanical properties and the microstructure of lightweight sand concrete", J. Adhes. Sci. Technol., vol. 30, no. 13, pp. 1391-1412, 2016

[http://dx.doi.org/10.1080/01694243.2016.1146390]

[27] B. Belhadj, M. Bederina, Z. Makhloufi, A. Goullieux, and M. Quéneudec, "Study of the thermal performances of an exterior wall of barley straw sand concrete in an arid environment", Energy Build., vol. 87, pp. 166-175, 2015.

[http://dx.doi.org/10.1016/j.enbuild.2014.11.034]

[28] L.A. Chaabane, E.H. Kadri, Y. Sebaibi, and H. Soualhi, "Dune sand and pumice impact on mechanical and thermal lightweight concrete properties", Constr. Build. Mater., vol. 133, pp. 209-218, 2017. [http://dx.doi.org/10.1016/j.conbuildmat.2016.12.043]

[29] O. Elalaoui, E. Ghorbel, and M.B. Ouezdou, "Influence of flame retardant addition on the durability of epoxy based polymer concrete after exposition to elevated temperature", Constr. Build. Mater., vol. 192, pp. 233-239, 2018

[http://dx.doi.org/10.1016/j.conbuildmat.2018.10.132]

[30] D. Zhang, X. Huang, and Y. Zhao, "Investigation of the shape, size, angularity and surface texture properties of coarse aggregates", Constr. Build. Mater., vol. 34, pp. 330-336, 2012.

[http://dx.doi.org/10.1016/j.conbuildmat.2012.02.096]

[31] K. Jafari, and V. Toufigh, "Experimental and analytical evaluation of rubberized polymer concrete", Constr. Build. Mater., vol. 155, pp. 495-510, 2017. [http://dx.doi.org/10.1016/j.conbuildmat.2017.08.097]

[32] V. Toufigh, M. Hosseinali, and S.M. Shirkhorshidi, "Experimental study and constitutive modeling of polymer concrete's behavior in compression", Constr. Build. Mater., vol. 112, pp. 183-190, 2016. [http://dx.doi.org/10.1016/j.conbuildmat.2016.02.100]

[33] A.S.T.M. Standard, ASTM C579: Standard test methods for compressive strength of chemical-resistant mortars, grouts, monolithic surfacings, and polymer concretes, United States, 2012.

[34] A.S.T.M. Standard, ASTM C580: Standard test method for flexural strength and modulus of elasticity of chemical-resistant mortars, grouts, monolithic surfacings, and polymer concretes, United States, 2012.

[35] Y. Ohama, and K. Demura, "Relation between curing conditions and compressive strength of polyester resin concrete", Int. J. Cem. Compos. Lightweight Concr., vol. 4, no. 4, pp. 241-244, 1982. [http://dx.doi.org/10.1016/0262-5075(82)90028-8]

[36] NF EN 196-1, Methods of testing cement - Part 1: Determination of strength, AFNOR,

[37] TS EN 206-1 Concrete: Part 1- Specification, performance, production and conformity, Ankara (Turkey),

[38] W. Maherzi, I. Ennahal, M. Benzerzour, Y. Mammindy-Pajany, and N.E. Abriak, "Study of the polymer mortar based on dredged sediments and epoxy resin: Effect of the sediments on the behavior of the polymer mortar", Powder Technol., vol. 361, pp. 968-982, 2020. [http://dx.doi.org/10.1016/j.powtec.2019.10.104]

[39] P. Mani, A.K. Gupta, and S. Krishnamoorthy, "Comparative study of epoxy and polyester resin-based polymer concretes", Int. J. Adhes. Adhes., vol. 7, no. 3, pp. 157-163, 1987.

[http://dx.doi.org/10.1016/0143-7496(87)90071-6]

[40] M.C.S. Ribeiro, C.M.L. Tavares, and A.J.M. Ferreira, "Chemical resistance of epoxy and polyester polymer concrete to acids and salts", J. Polym. Eng., vol. 22, no. 1, pp. 27-43, 2002.

[http://dx.doi.org/10.1515/POLYENG.2002.22.1.27]

[41] K.S. Rebeiz, D.W. Fowler, and D.R. Paul, "Recycling plastics in polymer concrete for construction applications", J. Mater. Civ. Eng. vol. 5, pp. 237-248, 1993.

[http://dx.doi.org/10.1061/(ASCE)0899-1561(1993)5:2(237)]

[42] M. Golestaneh, G. Amini, G.D. Najafpour, and M.A. Beygi, "Evaluation of mechanical strength of epoxy polymer concrete with silica powder as filler", World Appl. Sci. J., vol. 9, no. 2, pp. 216-220, 2010 .

[43] W. Lokuge, and T. Aravinthan, "Effect of fly ash on the behaviour of polymer concrete with different types of resin", Mater. Des., vol. 51, pp. 175-181, 2013.

[http://dx.doi.org/10.1016/j.matdes.2013.03.078]

[44] M. Hassani Niaki, A. Fereidoon, and M. Ghorbanzadeh Ahangari, "Mechanical properties of epoxy/basalt polymer concrete: Experimental and analytical study", Struct. Concr., vol. 19, no. 2, pp. 366-373, 2018

[http://dx.doi.org/10.1002/suco.201700003]

[45] P.J.R.O. Nóvoa, M.C.S. Ribeiro, A.J.M. Ferreira, and A.T. Marques, "Mechanical characterization of lightweight polymer mortar modified with cork granulates", Comp. sci. tech., vol. 64, pp. 2197-2205, 2004.

[46] H. Haddad, and M. Al Kobaisi, "Optimization of the polymer concrete used for manufacturing bases for precision tool machines", Compos., Part B Eng., vol. 43, no. 8, pp. 3061-3068, 2012. [http://dx.doi.org/10.1016/j.compositesb.2012.05.003]

(C) 2020 Kerrida et al.

This is an open access article distributed under the terms of the Creative Commons Attribution 4.0 International Public License (CC-BY 4.0), a copy of which is available at: https://creativecommons.org/licenses/by/4.0/legalcode. This license permits unrestricted use, distribution, and reproduction in any medium, provided the original author and source are credited. 